\title{
Open repair of ruptured descending thoracic and thoracoabdominal aortic aneurysms
}

\author{
Mario Gaudino, MD, ${ }^{\mathrm{a}, \mathrm{b}}$ Christopher Lau, MD, ${ }^{\mathrm{a}}$ Monica Munjal, MS, ${ }^{\mathrm{a}}$ and Leonard N. Girardi, $\mathrm{MD}^{\mathrm{a}}$
}

\section{ABSTRACT}

Objective: To evaluate the results of the open repair of ruptured thoracic and thoracoabdominal aortic aneurysms.

Methods: From January 1997, a total of 100 consecutive open repairs of ruptured thoracic or thoracoabdominal aortic aneurysms were performed (43 thoracic and 57 thoracoabdominal). These patients were compared with contemporary cases that underwent repair of corresponding intact aneurysms. Propensity matching analysis was used to neutralize the differences in baseline characteristics.

Results: Patients with ruptured aneurysm had a significantly worse baseline clinical profile. The surgical strategy adopted was similar in intact and ruptured aneurysms, with the exception of lower use of spinal drainage, intercostal reimplantation, and associated procedures in those with rupture $(P<.001$ for all comparisons). In the unmatched population, in-hospital mortality was $14 \%$ in the rupture group, and $4.2 \%$ in the intact group $(P=.01)$. The incidence of postoperative myocardial infarction, need for tracheostomy, and need for dialysis was $3 \%, 19 \%$, and $11 \%$ in the rupture, and $0.8 \%$, $5.7 \%$, and $4.2 \%$ in the intact series $(P \leq .01$ for all variables). Five-year survival was $47.5 \%$ for the rupture, and $59.5 \%$ for the intact series $(P<.001)$. In the matched population, no differences in postoperative and long-term outcome were found between the rupture and intact cases. Logistic regression analysis showed that female gender, urgent/emergent operation, and preoperative hemodialysis, but not ruptured aneurysm, were predictive of in-hospital major adverse events.

Conclusions: Open repair of ruptured thoracic and thoracoabdominal aortic aneurysms can be performed with a gratifying rate of success. For patients with similar preoperative comorbidities, postoperative survival is not affected by the presence of a ruptured aneurysm. (J Thorac Cardiovasc Surg 2015;150:814-23)

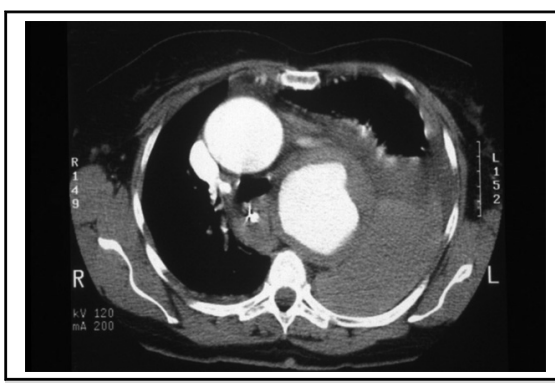

Ruptured thoracoabdominal aortic aneurysm

Central Message

In 100 patients with ruptured thoracic or thoracoabdominal aneurysms, operative mortality was $14 \%$, and 5 -year survival was $47.5 \%$.

\section{Perspective}

The optimal treatment for ruptured thoracic and thoracoabdominal aortic aneurysms is still a matter of debate. We report a series of 100 consecutive cases treated with open surgery with a gratifying rate of recovery. For patients with similar preoperative comorbidities, postoperative survival was not affected by the presence of a ruptured aneurysm.

See Editorial page 767.
Descending thoracic aneurysm (DTA) and thoracoabdominal aortic aneurysm (TAAA) repair remain formidable surgical procedures. Although the perioperative mortality of

From the a Department of Cardiothoracic Surgery, Weill Cornell Medical College, New York, NY; and ${ }^{\mathrm{b}}$ Department of Cardiovascular Sciences, Catholic University, Rome, Italy.

Read at the 95th Annual Meeting of The American Association for Thoracic Surgery, Seattle, Washington, April 25-29, 2015.

Received for publication April 26, 2015; revisions received June 12, 2015; accepted for publication June 19, 2015; available ahead of print July 27, 2015.

Address for reprints: Leonard N. Girardi, MD, Department of Cardiothoracic Surgery, Weill Cornell Medical College, 525 E 68th St, Ste M404, New York, NY 10065 (E-mail: Ingirard@med.cornell.edu).

0022-5223/\$36.00

Copyright (c) 2015 by The American Association for Thoracic Surgery

http://dx.doi.org/10.1016/j.jtcvs.2015.06.077 elective aneurysm repair has declined substantially over the past 2 decades,${ }^{1-3}$ morbid postoperative complications remain and often dissuade patients and referring physicians from seeking a surgical consultation, even when large aneurysms are present.

A less-invasive endovascular option, thoracic endovascular aneurysm repair (TEVAR), has dramatically increased the number of patients undergoing thoracic aneurysm repair in the United States. ${ }^{4,5}$ TEVAR for TAAA repair is evolving as well. ${ }^{6}$ However, the elimination of a major thoracotomy has not dramatically reduced the incidence of life-threatening events, such as stroke, spinal cord injury (SCI), and renal failure, even in low-risk patients. Endoleaks occur at an unsettlingly high rate, and the true incidence of fatal 


\section{Abbreviations and Acronyms \\ CI = confidence interval \\ DTA = descending thoracic aneurysm \\ MAE = major adverse events \\ $\mathrm{PSM}=$ propensity-score matching \\ SCI $=$ spinal cord injury \\ TAAA $=$ thoracoabdominal aortic aneurysm \\ TEVAR $=$ thoracic endovascular aneurysm repair}

aneurysm rupture after TEVAR is unknown. Evidence is accumulating that even in cohorts with similar comorbid conditions, open repair may provide patients with superior long-term survival. ${ }^{7}$

Despite ample evidence that large and/or expanding thoracic aneurysms have a high incidence of rupture or dissection, ${ }^{8,9}$ the number of reported thoracic aneurysm ruptures has risen over the past decade. ${ }^{4}$ Once a thoracic aneurysm ruptures, the incidence of death and all major postoperative complications increases dramatically, even in high-volume centers. ${ }^{10-13}$ In a previous article, our group reported a mortality of $18.5 \%$ in 41 patients who had thoracic aneurysm rupture. ${ }^{14}$

As a tertiary-care aortic referral center, we continue to care for a large volume of patients with both DTA and TAAA. A substantial number of patients need care for acute rupture. We sought to examine our contemporary experience with ruptured DTA and TAAA. In addition, we wished to evaluate the role of the acute event in outcome, rather than underlying patient comorbidities, by utilizing propensity matching to compare patients with rupture to their elective counterparts.

\section{METHODS}

\section{Patient Population, Definitions, and End-Points}

This study was approved by the Weill Cornell Medical College review board. The need for individual patient consent was waived.

Review of prospectively collected data from the Weill Cornell Medical College Department of Cardiothoracic Surgery aortic surgery database was conducted to identify all consecutive patients who underwent open repair of ruptured TAAA or DTA from January 1997 to September 2014. Cases with traumatic aortic rupture were not included in the present analysis.

Primary endpoints were operative and follow-up death from any cause. Secondary endpoints were the incidence of major postoperative complications and a composite of major adverse events (MAE) after surgery (operative death and major postoperative complications). Classification of the aneurysms was based on their anatomic extent, according to Crawford. ${ }^{5}$

\section{Surgical Technique}

Details of our surgical procedure have been previously published. ${ }^{14}$ Briefly, a fifth, sixth, or seventh intercostal space thoracotomy or thoracoabdominal incision was utilized. Partial resection of adjacent ribs was performed as needed for additional exposure.

In patients with free rupture, or in those with isolated descending aortic pathology, a clamp- and-sew technique was our primary strategy. In those with TAAAs of extent I, III, or IV, a primary clamp-and-sew strategy was utilized, and adjuncts such as cold renal perfusion or blood visceral perfusion were added if the visceral and renal vessels were involved. ${ }^{15}$ In contained, ruptured, extent-II aneurysms, and stable, contained, ruptured, acute type B dissections, left heart bypass was preferred. Finally, when proximal aortic control was unattainable, cardiopulmonary bypass and circulatory arrest were utilized. Rapid reinfusion of shed blood was performed utilizing a Belmont warm rapid infusion system (Belmont Instrument Corporation, Billerica, Mass). When partial bypass, or the clamp-and-sew technique, was utilized, core temperature was allowed to passively decline to $33^{\circ} \mathrm{C}$ before the aorta was crossclamped.

Reimplantation of intercostal arteries was performed with the inlayinclusion technique. Visceral and renal arteries were either reimplanted or bypassed, as dictated by the patient's anatomy. Hemashield Dacron grafts (Maquet Getinge Group, Oakland, NJ) were utilized. Preoperative spinal drain insertion was performed in hemodynamically stable patients. In unstable patients, spinal drain insertion was performed immediately after surgery, before transporting the patient to the intensive care unit. Drains were maintained with an intrathecal pressure of $<12 \mathrm{~cm} \mathrm{H}_{2} \mathrm{O}$, for 72 hours after surgery. Mean arterial pressure was maintained at $>85 \mathrm{~mm} \mathrm{Hg}$.

\section{Statistical Analysis}

Data were stored using Microsoft Access 2010 software (Microsoft, Redmond, Washington) and analyzed using IBM SPSS Statistics, version 22 (SPSS, Inc, Chicago, Ill), R version 2.15.2 (R Foundation for Statistical Computing), IBM SPSS Statistics-Essentials for R 22.0 (Thoemmes, Bristol, UK) and MatchIt package (freely available at http://gking. harvard.edu/matchit). Data from the study population were compared using $\chi^{2}$ for categoric variables and Student's $t$ test for continuous variables. Backward stepwise logistic regression analysis was used to assess for significant demographic and preoperative predictors of inhospital MAE.

Propensity-score matching (PSM) was used to adjust for baseline differences and reduce confounding according to a described method. ${ }^{7,8}$ Selected variables for PSM were all the preoperative clinical variables that resulted in significant differences between groups on univariate analysis, and the extent and type of the aneurysm (DTA vs TAAA). Postoperative survival was assessed using the Kaplan-Meier method. Groups were compared using log-rank analysis.

\section{RESULTS \\ Patient Profiles}

During the study period, 100 consecutive patients underwent open repair of ruptured TAAA or DTA (57 TAAA; 43 DTA). The rupture was located in the DTA in most cases (90 of 100), and was contained in 41. Twenty-seven patients were in shock at the time of presentation. The main preoperative features of the patients are summarized in Table 1.

The mean aortic diameter at the time of rupture was $7.1 \pm$ $2.0 \mathrm{~cm}$. Aortic diameter was $8.1 \pm 1.5 \mathrm{~cm}$ in patients with chronic dissection, versus $7.0 \pm 2.0 \mathrm{~cm}$ in the rest of the population $(P=.04)$.

These data were compared to those of 575 consecutive contemporary cases that underwent repair of intact TAAA or DTA. The results of this comparison are shown in Table 1. Patients in the group with rupture had a higher incidence of smoking, chronic pulmonary disease, previous cerebrovascular accident, peripheral vascular disease, diabetes, preoperative renal dysfunction, $\mathrm{SCI}$, and preoperative shock $(P \leq .01$ for all variables). 
TABLE 1. Preoperative characteristics

\begin{tabular}{lccc}
\hline \multicolumn{1}{c}{ Characteristic } & $\begin{array}{c}\text { Rupture series } \\
(\mathbf{n}=\mathbf{1 0 0})\end{array}$ & $\begin{array}{c}\text { Intact series } \\
(\mathbf{n}=\mathbf{5 7 5})\end{array}$ & $\begin{array}{c}\boldsymbol{P} \\
\text { value }\end{array}$ \\
\hline Age (mean \pm SD) & $67.2 \pm 14.3$ & $64.3 \pm 14.4$ & .06 \\
Gender, male & $61(61)$ & $336(58.4)$ & .63 \\
Smoking & $94(94)$ & $423(73.6)$ & $<.001$ \\
Previous coronary & $20(20)$ & $115(20)$ & 1.0 \\
$\quad$ revascularization & & & \\
Hypertension & $97(97)$ & $553(96.2)$ & .686 \\
Chronic pulmonary disease & $60(60)$ & $216(37.6)$ & $<.001$ \\
Previous stroke & $8(8)$ & $29(5.1)$ & $<.001$ \\
Peripheral vascular disease & $38(38)$ & $147(25.6)$ & .01 \\
Diabetes & $17(17)$ & $44(7.7)$ & .003 \\
Family history of aneurysm & $1(1)$ & $30(5.2)$ & .06 \\
Renal dysfunction & $59(59)$ & $147(25.5)$ & $<.001$ \\
Previous cardiac surgery & $38(38)$ & $290(50.4)$ & .09 \\
Preoperative spinal cord injury & $7(7)$ & $3(0.5)$ & $<.001$ \\
Aneurysm extent I or II & $48(48)$ & $309(53.7)$ & .06 \\
Aneurysm size (mm) (mean \pm SD) & $7.1 \pm 2.0$ & $6.9 \pm 1.4$ & .140 \\
Shock & $27(27)$ & $1(0.2)$ & $<.001$ \\
Emergent operation & $96(96)$ & $115(20)$ & $<.001$ \\
\hline Data are presented as n (\%), unless otherwise noted. SD, Standard deviation. & \\
& & &
\end{tabular}

\section{Surgical Data}

Surgical details of the rupture and intact groups are given in Table 2. In the rupture group, the clamp-and-sew technique was used in 68 patients (21 DTA; 47 TAAA); partial bypass was adopted in 21 (12 DTA; 9 TAAA); and deep hypothermic circulatory arrest in 11 (10 DTA; 1 TAAA). The use of deep hypothermic circulatory arrest was significantly more frequent among DTA cases $(P<.001)$, and the clamp-and-sew technique was used more frequently in TAAA patients $(P<.001)$.

Concomitant procedures were performed in $35 \%$ of the rupture group, and $30.1 \%$ of the intact series $(P<.001)$. No differences in surgical technique were evident between the rupture and intact series. Spinal drainage was used in $65 \%$ of rupture cases versus $85.7 \%$ of the control group $(P<.001)$; intercostal reimplantation was performed in $22 \%$ of cases in the rupture group versus $43.8 \%$ in the

TABLE 2. Intraoperative data

\begin{tabular}{lccr}
\hline \multicolumn{1}{c}{ Variable } & $\begin{array}{c}\text { Rupture series } \\
(\mathbf{n = 1 0 0 )}\end{array}$ & $\begin{array}{c}\text { Intact series } \\
(\mathbf{n = 5 7 5 )}\end{array}$ & $\begin{array}{c}\boldsymbol{P} \\
\text { value }\end{array}$ \\
\hline Clamp-and-sew technique & $68(68)$ & $366(63.7)$ & .402 \\
Circulatory arrest & $11(11)$ & $49(8.5)$ & .422 \\
Partial bypass & $21(21)$ & $160(27.8)$ & .155 \\
Spinal drainage & $65(65)$ & $493(85.7)$ & $<.001$ \\
Any intercostal reimplantation & $22(22)$ & $252(43.8)$ & $<.001$ \\
More than 1 set of intercostals & $11(11)$ & $132(22.9)$ & .001 \\
$\quad$ reimplanted & & & \\
Concomitant procedures & $35(35)$ & $173(30.1)$ & $<.001$ \\
Cold renal perfusion & $15(15)$ & $131(22.8)$ & .21 \\
\hline Da
\end{tabular}

Data are presented as n (\%), unless otherwise noted.
TABLE 3. In-hospital outcome in the unmatched population

\begin{tabular}{lccc}
\hline \multicolumn{1}{c}{ Outcome } & $\begin{array}{c}\text { Rupture series } \\
(\mathbf{n = 1 0 0 )}\end{array}$ & $\begin{array}{c}\text { Intact series } \\
(\mathbf{n}=\mathbf{5 7 5})\end{array}$ & $\begin{array}{c}\boldsymbol{P} \\
\text { value }\end{array}$ \\
\hline Operative mortality & $14(14)$ & $24(4.2)$ & .01 \\
Myocardial infarction & $7(7)$ & $5(0.8)$ & .004 \\
Stroke & 1 & $5(0.8)$ & .86 \\
Tracheostomy & $19(19)$ & $33(5.7)$ & $<.001$ \\
New dialysis & $11(11)$ & $24(4.2)$ & .01 \\
Spinal cord injury & $5(5)$ & $14(2.4)$ & .16 \\
Recurrent nerve palsy & $9(9)$ & $38(6.6)$ & .38 \\
Re-exploration for bleeding & $2(2)$ & $14(2.4)$ & .79 \\
\hline
\end{tabular}

Data are presented as $\mathrm{n}(\%)$, unless otherwise noted.

intact series; and $11 \%$ of patients with rupture had $>1$ intercostal reimplantation, versus $22.9 \%$ of the intact series $(P$ $\leq .001$ for both). Cold renal perfusion during surgery was used in $15 \%$ of the patients with rupture, versus $22.7 \%$ of the patients with intact aneurysm $(P=.21)$.

The median partial bypass and deep hypothermic circulatory arrest times were 32 minutes and 31 minutes, respectively, in the rupture group, and 28 minutes and 33 minutes, respectively, in the intact group $(P=.151$ and $P=.66$, respectively). The median crossclamp time for patients who underwent operation with the clamp-and-sew technique was 31 minutes in the group with rupture, and 33 minutes in the intact series $(P=.35)$.

\section{In-Hospital Outcome}

Details of the postoperative outcome of the 2 groups are given in Table 3. Operative mortality was 14\% (14 of 100) in the rupture group, and $4.2 \%$ (24 of 575) in the intact series $(P=.01)$. Mortality was $13.9 \%$ (6 of 43 ) and $14 \%$ (8 of 57 ) versus $2.9 \%$ (5 of 167 ) and $4.6 \%$ (19 of 408 ) for DTA and TAAA, respectively, in the rupture and intact groups ( $P=.99$ and $P=.36$ for intragroup comparison). For patients in the rupture group who presented with preoperative shock, mortality was $29.6 \%$ ( 8 of $27 ; P=.02$, vs patients without preoperative shock). Causes of operative death were respiratory failure (5 cases; $35.7 \%$ ); myocardial infarction (4 patients; $28.5 \%$ ); and stroke, arrhythmia, multiple organ failure, sepsis, and malperfusion (1 case of each).

The incidence of postoperative myocardial infarction, need for tracheostomy, and dialysis required by newonset renal failure was $7 \%, 19 \%$, and $11 \%$, respectively, in the rupture group, and $0.8 \%, 5.7 \%$, and $4.2 \%$ in the intact series $(P \leq .01$ for all comparisons). New-onset SCI occurred in $5 \%$ of cases in the rupture group versus $2.4 \%$ in the intact group $(P=.16)$; left recurrent nerve injury occurred in $9 \%$ of the rupture cases versus $6.6 \%$ of the intact group $(P=.38)$. Of the 7 patients in the rupture group who had preoperative SCI, $1(14.2 \%)$ had postoperative paraplegia; in the other 6 , the neurologic deficit resolved after surgery. 
TABLE 4. Univariate predictors of death in the rupture series

\begin{tabular}{lccc}
\hline \multicolumn{1}{c}{ Predictor } & Dead $(\mathbf{n}=\mathbf{1 4})$ & Alive $(\mathbf{n}=\mathbf{8 6})$ & $\boldsymbol{P}$ value \\
\hline Male gender & $7(50)$ & $54(62.8)$ & .363 \\
Smoking & $14(100)$ & $80(93.0)$ & .308 \\
Previous coronary & $3(21.4)$ & $17(19.8)$ & .885 \\
$\quad$ revascularization & & & \\
Hypertension & $14(100)$ & $83(96.5)$ & .478 \\
Chronic pulmonary disease & $12(85.7)$ & $48(55.8)$ & .034 \\
Previous stroke & $3(21.4)$ & $5(5.8)$ & .046 \\
Peripheral vascular disease & $9(64.3)$ & $29(33.7)$ & .029 \\
Diabetes & $7(50.0)$ & $10(11.6)$ & $<.001$ \\
Family history of aneurysm & $0(0.0)$ & $1(1.2)$ & .685 \\
Renal dysfunction & $12(85.8)$ & $47(54.7)$ & .028 \\
Previous cardiac surgery & $6(42.9)$ & $32(37.2)$ & .686 \\
Preoperative spinal cord injury & $3(21.4)$ & $4(4.7)$ & .023 \\
Thoracoabdominal aneurysm & $8(57.1)$ & $49(57.0)$ & .991 \\
Aneurysm extent I or II & $6(75.0)$ & $42(48.8)$ & .678 \\
Shock & $8(57.1)$ & $19(22.1)$ & .006 \\
Emergent operation & $14(100)$ & $82(95.3)$ & .410 \\
\hline
\end{tabular}

Data are presented as $n(\%)$, unless otherwise noted.

Univariate analysis showed that the preoperative variables associated with operative death in the rupture series were: chronic pulmonary disease, previous stroke, peripheral vascular disease, diabetes, renal failure, SCI, and shock (Table 4). Logistic regression analysis was not performed, owing to the limited number of events.

In the overall population, logistic regression analysis identified female gender, urgent/emergent operation, and preoperative hemodialysis as predictors of in-hospital

TABLE 5. Preoperative characteristics in the propensity-scorematched population

\begin{tabular}{lccc}
\hline \multicolumn{1}{c}{ Characteristic } & $\begin{array}{c}\text { Rupture series } \\
(\mathbf{n}=\mathbf{6 1})\end{array}$ & $\begin{array}{c}\text { Intact series } \\
(\mathbf{n}=\mathbf{6 1})\end{array}$ & $\begin{array}{c}\boldsymbol{P} \\
\text { value }\end{array}$ \\
\hline Age (y; mean \pm SD) & $66.8 \pm 14.0$ & $65.6 \pm 12.4$ & .623 \\
Male gender & $35(57.4)$ & $33(54.1)$ & .855 \\
Smoking & $56(91.8)$ & $57(93.4)$ & .729 \\
Previous coronary & $11(18.0)$ & $9(14.8)$ & .625 \\
$\quad$ revascularization & & & \\
Hypertension & $58(95.1)$ & $61(100.0)$ & .079 \\
Chronic pulmonary disease & $37(60.7)$ & $37(60.7)$ & $\mathrm{NS}$ \\
Previous stroke & $3(4.9)$ & $3(4.9)$ & .709 \\
Peripheral vascular disease & $18(29.5)$ & $16(26.2)$ & .686 \\
Diabetes & $9(14.8)$ & $8(13.1)$ & .794 \\
Family history of aneurysm & $1(1.6)$ & $1(1.6)$ & $\mathrm{NS}$ \\
Renal dysfunction & $26(42.5)$ & $29(47.5)$ & .958 \\
Previous cardiac surgery & $20(32.8)$ & $18(29.5)$ & .415 \\
Preoperative spinal cord injury & $4(6.6)$ & $1(1.6)$ & .171 \\
Aneurysm extent I or II & $30(49.2)$ & $32(52.5)$ & .899 \\
Aneurysm size (mm) (mean \pm SD) & $7.2 \pm 2.1$ & $7.2 \pm 2.0$ & .874 \\
Shock & $14(23.0)$ & $1(1.6)$ & $<.001$ \\
Emergent operation & $57(93.4)$ & $57(93.4)$ & NS \\
\hline Data are presented as n (\%), unless otherwise noted. NS, Nonsignificant; $S D$, \\
standard deviation. & \multicolumn{3}{c}{}
\end{tabular}

TABLE 6. In-hospital outcome in the propensity-score-matched population

\begin{tabular}{lccc}
\hline \multicolumn{1}{c}{ Outcome } & $\begin{array}{c}\text { Rupture series } \\
(\mathbf{n}=\mathbf{6 1})\end{array}$ & $\begin{array}{c}\text { Intact series } \\
(\mathbf{n}=\mathbf{6 1})\end{array}$ & $\boldsymbol{P}$ value \\
\hline Operative mortality & $0(0)$ & $1(1.6)$ & .315 \\
Myocardial infarction & $2(3.3)$ & $0(0)$ & .157 \\
Stroke & $0(0)$ & $0(0)$ & .604 \\
Tracheostomy & $12(19.7)$ & $9(14.8)$ & .364 \\
New dialysis & $4(6.6)$ & $6(9.8)$ & .301 \\
Spinal cord injury & $4(6.5)$ & $1(1.6)$ & .354 \\
\hline
\end{tabular}

Data are presented as $n(\%)$, unless otherwise noted.

MAE (odds ratios $[95 \% \mathrm{CI}]$, respectively: 2.32 [1.373.92]; 2.65 [1.42-4.96], and 4.54 [1.46-14.07]; $P=.002$, $P=.002$, and $P=.009$, respectively). Rupture of the aneurysm was not predictive of in-hospital MAE (odds ratio: 1.78; 95\% CI: 0.62-5.07; $P=.27$ ).

Propensity-score matching analysis neutralized the differences in baseline characteristics between the 2 patient groups and resulted in 2 pairs of 61 patients who had almost identical preoperative features (Table 5). In the matched population, no significant differences in mortality or incidence of major postoperative complications were found between the rupture and intact groups (Table 6).

\section{Long-Term Survival}

In the unmatched population, 5-year survival was $47.5 \%$ for the rupture group and $59.5 \%$ for the intact series $(P<.001)$. Long-term survival curves are shown in Figures 1 and 2. In the propensity-score-matched groups, 5 -year survival was $45.1 \%$ for the rupture group, and $49.9 \%$ for the intact series $(P=.21)$ (Figure 3$)$. During the follow-up, 4 patients of the 86 survivors of repair of ruptured aneurysm underwent reoperation on the thoracoabdominal aorta for pseudoaneurysm ( 2 patients) or

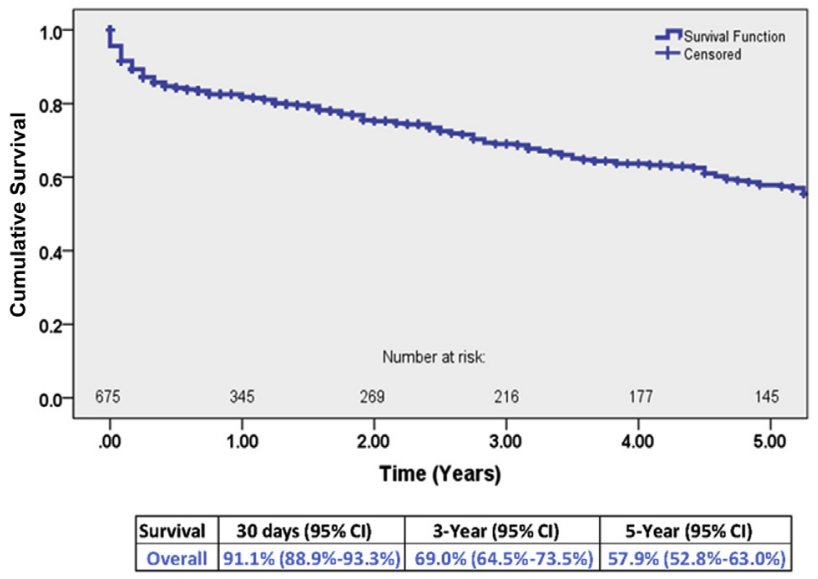

FIGURE 1. Kaplan-Meier survival curves in the overall population (for total cohort). $C I$, Confidence interval. 


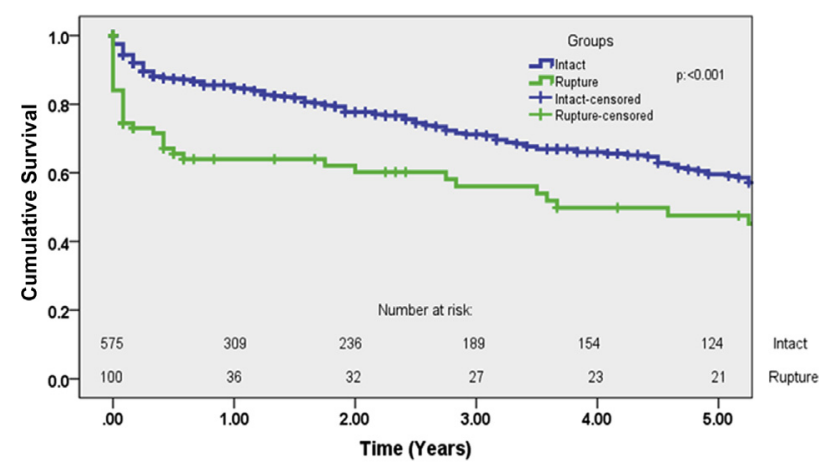

\begin{tabular}{|c|c|c|c|}
\hline Survival & 30 days $(95 \% \mathrm{Cl})$ & 3-Year $(95 \% \mathrm{Cl})$ & 5-Year $(95 \% \mathrm{Cl})$ \\
\hline Intact & $94.0 \%(92.0 \%-96.0 \%)$ & $71.2 \%(66.5 \%-75.9 \%)$ & $59.5 \%(53.8 \%-65.2 \%)$ \\
\hline Rupture & $73.5 \%(64.3 \%-82.7 \%)$ & $56.0 \%(44.2 \%-67.8 \%)$ & $47.5 \%(35.0 \%-60.0 \%)$ \\
\hline
\end{tabular}

FIGURE 2. Kaplan-Meier survival curves, rupture versus intact, in the unmatched series. $C I$, Confidence interval.

dilatation of residual native aorta ( 2 patients). The 5-year freedom from reoperation for the rupture group was $90.6 \%$.

\section{DISCUSSION}

Ruptured thoracic aneurysms are rare entities, with an estimated incidence of 5 per 100,000. Approximately $30 \%$ of all ruptures in the thoracic aorta are localized to the descending segment, and most patients die before receiving treatment. ${ }^{16}$ The risks of thoracic aneurysm rupture have been well established in natural history studies. Those that exceed $5.5 \mathrm{~cm}$ in diameter have an annual rate of either rupture or dissection ${ }^{8,9}$ of $>15 \%$.

Despite a significant reduction in the morbidity and mortality associated with elective DTA and TAAA repair, patients and their referring physicians continue to endure the risk of an aortic catastrophe in the hope of avoiding major complications, such as SCI, stroke,
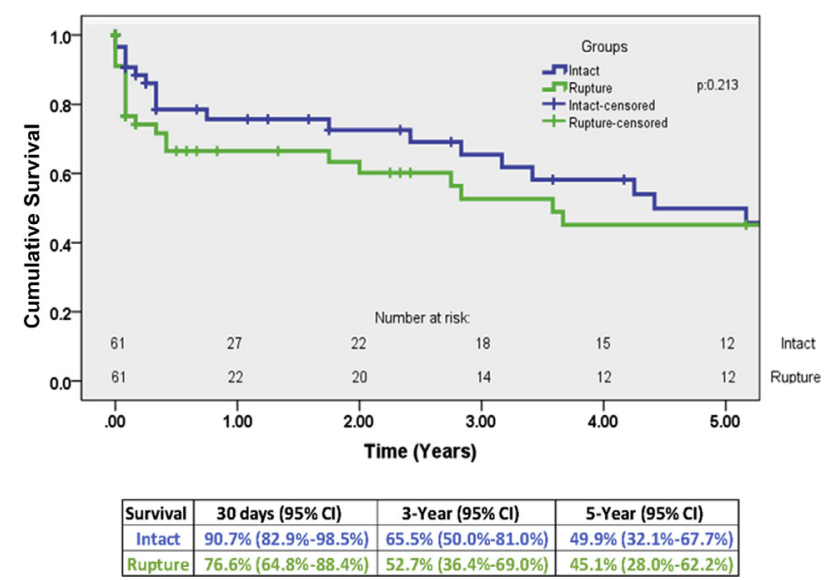

FIGURE 3. Kaplan-Meier survival curves in the propensity-scorematched populations. $C I$, Confidence interval. and renal failure. This approach has contributed to an increasing number of patients who have aneurysm rupture. In 2 large Medicare studies, nearly $9 \%$ of all patients having DTA repair presented with a ruptured aneurysm. ${ }^{4,5}$ The outcomes in this high-risk cohort, regardless of whether the patient had an open or endovascular repair, were predictably worse than those in the elective setting. However, many patients presented to small hospitals where providers had limited experience in either open or endovascular thoracic aortic surgery. The mortality in this setting is $>3$-fold higher than it is in large tertiary-care centers. ${ }^{17} \mathrm{~A}$ more thorough examination of a contemporary experience with open repair of ruptured thoracic aneurysms in a highvolume aortic referral center seemed warranted.

The need for earlier intervention for thoracic aneurysms is supported by 2 previous studies examining outcomes in patients who have had open repair of ruptured DTAs and TAAAs. Crawford and colleagues ${ }^{18}$ presented one of the earliest, and still the largest, single-center experiences with ruptured thoracic aneurysms. In 117 consecutive patients, the median aortic diameter at the time of presentation was $>8 \mathrm{~cm}$. The 30-day mortality rate was a very respectable $24 \%$, despite one quarter of their patients presenting in shock. This mortality rate was $>3$-fold higher than that seen in patients undergoing elective repair. An additional concomitant increase occurred in the incidence of permanent SCI, and a nearly 5 -fold increase occurred in the incidence of dialysisdependent renal failure.

A decade later, we reported on 40 consecutive patients who presented with thoracic aneurysm rupture. ${ }^{14} \mathrm{We}$, too, found the mean aortic diameter at the time of presentation to be substantially larger than that in patients undergoing elective repair $(8.2 \mathrm{~cm}$ vs $6.6 \mathrm{~cm})$. Although our operative mortality was $17.5 \%$, this risk was 9-fold higher than the risk for those we repaired in the elective setting. Surprisingly, the risk of SCI and postoperative dialysis was not significantly higher, but as found in the Crawford study, cardiac events were the primary cause of mortality.

Approximately $20 \%$ to $30 \%$ of all patients with a ruptured TAAA or DTA present in shock, and nearly one half are hemodynamically unstable when they are taken to the operating room. ${ }^{19}$ In the present series, $27 \%$ presented in shock, a state highly predictive of postoperative mortality on univariate analysis ( 8 of $27 ; 29.6 \% ; P<.02)$. Shock necessitated rapid intervention and significantly reduced our ability to institute modern end-organ protection strategies, such as spinal drainage or intercostal reimplantation. Although this did not significantly increase the incidence of permanent neurologic injury, patients with rupture were more likely to develop the need for dialysis $(11 \%$ vs $4.2 \% ; P<.01)$ or a tracheostomy $(19 \%$ vs $5.7 \%$; 
$P<.001)$ after surgery, compared with their elective-repair counterparts.

The surgical strategy for repair of ruptured TAAA and DTA is individually tailored based on aneurysm extent, hemodynamic conditions, and the risk profile of the patient. Although we advocate for use of modern endorgan protection adjuncts, the operative strategy and, at times, even the extent of the repair, must in fact be individualized for every patient. Most of our repairs were complete extirpation of the aneurysm; the rare patient with extreme instability or advanced age occasionally mandated a more conservative approach in the operating room. Those surviving such an unusual constellation of circumstances, of course, require serial imaging to follow the retained aneurysm segments.

Aneurysm rupture also forced us to proceed without being able to correct significant coronary artery disease. Similar to previous studies, ${ }^{14,18,20,21}$ myocardial infarction was significantly predictive of perioperative mortality and was responsible for nearly $30 \%$ of the deaths in this series. We had previously demonstrated the benefits of aggressive identification and correction of coronary artery disease before open elective repair of DTAs and TAAAs. ${ }^{2}$ However, we had not given consideration to this possibility in the setting of a rupture.

Patel and colleagues ${ }^{20}$ recognized as well the poor prognosis associated with a perioperative myocardial infarction, as nearly one quarter of the deaths in their series were cardiac in origin. ${ }^{20}$ In those with significant cardiac histories, they performed TEVAR when anatomically possible. None of these patients experienced clinically significant ischemia. However, in those hemodynamically stable patients who were unsuitable for an endovascular repair, they performed coronary angiography and percutaneous coronary intervention with a bare metal stent, immediately before going to the operating room. One additional patient underwent concomitant coronary artery bypass grafting at the time of DTA repair. Although 1 of these 2 patients died of a retrograde type A dissection, neither succumbed to myocardial ischemia. Given the grave prognosis associated with myocardial infarction and thoracic aneurysm repair, careful consideration should be given to emergent coronary angiography in a very selective subset of patients who present with a contained rupture, remain hemodynamically stable, and are at high risk for cardiac events. More experience with this algorithm is needed before widespread adoption of this method could be appropriately advocated.

As respiratory failure and myocardial infarction continue to plague open repair of ruptured DTA and TAAA, the fact that TEVAR quickly became a treatment strategy for this highly lethal problem was inevitable. The first TEVAR for a ruptured DTA was reported ${ }^{22}$ in 1997. After approval of TEVAR by the US Food and
Drug Administration for commercial use ${ }^{23}$ in 2005 , the number of patients being treated by endovascular repair has risen dramatically.

Conrad and colleagues, ${ }^{5}$ and subsequently Goodney and colleagues, ${ }^{4}$ reviewed $>15,000$ patients in the Medicare database who underwent DTA repair. Nearly $10 \%$ of those being treated presented with rupture, and $20 \%$ to $30 \%$ of those were treated with TEVAR. Although the perioperative mortality associated with TEVAR in the elective setting was not significantly better than that with the open approach (6.1\% TEVAR vs $7.1 \%$ open, $P<.07)$, the mortality reported for successful repair of ruptured DTAs was dramatically less than that seen with open surgery. In 1307 patients undergoing repair of a ruptured DTA, the in-hospital mortality with TEVAR was nearly half that seen with open surgery $^{4}(28.4 \%$ vs $45.6 \%$; $P<.0001)$. A meta-analysis looking at 224 patients with ruptured TA confirmed these findings. ${ }^{21}$

In 28 studies, a total of 143 patients underwent TEVAR, whereas 81 were repaired with traditional surgery. Again, those who underwent TEVAR had a mortality of nearly one half that of their open-surgery counterparts $(19 \%$ vs $33 \% ; P<.016)$. A similar 30-day mortality, $18.4 \%$, was also reported from 7 referral centers performing TEVAR for ruptured DTA. ${ }^{19}$ However, although endovascular repair of ruptured abdominal aortic aneurysm has been shown to be advantageous, with respect to both early and late survival, ${ }^{24}$ whether TEVAR offers patients with ruptured thoracoabdominal aneurysm similar advantages is unclear. A more thorough examination of perioperative data, as well as short-term and intermediate-term survival, may persuade one that open repair should not be abandoned quite yet.

The study by Jonker and colleagues, ${ }^{19}$ reviewing 87 patients from 7 aortic referral centers, performing TEVAR for ruptured thoracoabdominal aneurysm provides some sobering details. Although the technical success of the index procedure was $95.4 \%$, nearly $40 \%$ of patients required left subclavian artery coverage to achieve aneurysm exclusion. This likely contributed to the $8 \%$ stroke rate. Half of these strokes were fatal. Type I endoleaks, a condition highly associated with adverse outcomes in TEVAR, ${ }^{25}$ occurred in $18.4 \%$ of patients within 30 days of the index procedure. Another $2.3 \%$ developed one at 6 months. A total of $12.6 \%$ of patients required a second procedure within 17 days of their TEVAR.

All attempts at endovascular repair failed for 4 patients, and they died of either aneurysm rupture or a complication of the secondary procedure within 6 months of their initial presentation. An alarming number of patients presented within 6 months with infected endografts. The meta-analysis examining 143 patients who underwent TEVAR for ruptured thoracoabdominal aneurysm had similar problems with endoleaks. ${ }^{21}$ Unfortunately, 5 
perioperative survivors died of aneurysm-related causes within 139 days of their initial procedure. Sixty percent of these deaths were caused by aneurysm rupture, and the remaining $40 \%$ died of complications related to an infected endograft. In our experience, the need for further intervention is quite rare after open repair. Less than $10 \%$ of patients required any form of reintervention at 5 years, and no patients died from aneurysm rupture or infection.

Long-term survival after ruptured DTA or TAAA repair is worthy of discussion here. Despite the initial survival advantage provided in most series examining TEVAR, the benefit may prove to be short lived. Goodney and colleagues ${ }^{4}$ reported that the early survival advantage of TEVAR disappeared within the first 1.5 years after surgery. ${ }^{4}$ By life-table analysis, the 5-year survival after TEVAR repair of isolated ruptured DTA was only $23 \%$. Although most of our patients underwent higher-risk TAAA repair, the 5-year survival of our entire cohort was $47.5 \%$. Although this percentage was significantly lower than that seen in our elective population $(47.5 \%$ rupture vs $59.5 \%$ elective; $P<.001$ ), these differences disappeared with propensity-score matching and compare favorably with a less-invasive approach. These survival differences are not surprising considering that in the long-term follow-up after TEVAR, the perioperative survival advantage is now being seen to disappear by 2 years because of graft-related complications and the need for reinterventions. ${ }^{26,27}$

\section{Limitations}

This study is limited by its retrospective nature. In addition, the outcomes presented in this series are those of a high-volume, tertiary-care, aortic referral center and may not be extrapolated to smaller hospitals with limited experience or resources to deal with this high-risk patient population.

\section{CONCLUSIONS}

Open repair remains the gold standard surgical therapy for patients presenting with ruptured DTA and TAAA. The perioperative and long-term outcomes after open repair are encouraging, and after adjusting for patient-related factors, not significantly worse than those of elective cases. In those patients who are unstable, especially in smaller hospitals where resources and experience may be limited, TEVAR may provide a better opportunity for immediate survival. ${ }^{17}$ However, given that most patients with a rupture are stable, consideration should be given to transferring the patient to a center with the experience necessary to provide either open or endovascular repair.

You can watch a Webcast of this AATS meeting presentation by going to: http://webcast.aats.org/2015/Video/ Tuesday/04-28-15_612_1420_Gaudino.mp4.

\section{Conflict of Interest Statement}

Authors have nothing to disclose with regard to commercial support.

\section{References}

1. Lemaire SA, Price MD, Green SY, Zarda S, Coselli JS. Results of open thoracoabdominal aortic aneurysm repair. Ann Cardiothorac Surg. 2012;1: 286-92.

2. Girardi LN, Rabotnikov Y, Avgerinos DV. Preoperative percutaneous coronary intervention in patients undergoing open thoracoabdominal and descending thoracic aneurysm repair. J Thorac Cardiovasc Surg. 2014;147:163-8.

3. Estrera AL, Jan A, Sandhu H, Shalhub S, Medina-Castro M, Nguyen TC, et al. Outcomes of open repair for chronic descending thoracic aortic dissection. Ann Thorac Surg. 2015;99:786-94.

4. Goodney PP, Travias L, Lucas FL, Fillinger MF, Goodman GC, Cronenwett JL, et al. Survival after open versus endovascular thoracic aortic aneurysm repair in an observational study of the Medicare population. Circulation. 2011;124: 2661-9.

5. Conrad MF, Ergul EA, Patel VI, Paruchuri V, Kwolek CJ, Cambria RP. Management of diseases of the descending thoracic aorta in the endovascular era: a Medicare population study. Ann Surg. 2010;252:603-10.

6. Guillou M, Bianchini A, Sobocinski J, Maurel B, D'elia P, Tyrrell M, et al. Endovascular treatment of thoracoabdominal aortic aneurysms. J Vasc Surg. 2012; 56:65-73.

7. Lingala B, Fischbein MP, Woo YJ, Mitchell RS, Miller DC, Dake MD. TEVAR versus open descending thoracic aortic repair for the treatment of thoracic aortic aneurysms: an analysis of the Medicare database. Circulation. 2014;130: A12173.

8. Elefteriades JA. Natural history of thoracic aortic aneurysms: indications for surgery, and surgical versus nonsurgical risks. Ann Thorac Surg. 2002;74: S1877-80.

9. Davies RR, Goldstein LJ, Coady MA, Tittle SL, Rizzo JA, Kopf GS, et al. Yearly rupture or dissection rates for thoracic aortic aneurysms: simple prediction based on size. Ann Thorac Surg. 2002;73:17-27.

10. Kilic A, Shah AS, Black JH III, Whitman JR, Yuh DD, Cameron DE, et al. Trend in repair of intact and ruptured descending thoracic aortic aneurysms in the United States: a population-based analysis. J Thorac Cardiovasc Surg. 2014; 147:1855-60.

11. Lemaire SA, Rice DC, Schmitting ZC, Coselli JS. Emergency surgery for thoracoabdominal aneurysms with acute presentation. J Vasc Surg. 2002;35:1171-8.

12. Lewis ME, Ranasinghe AM, Revell MP, Bonser RS. Surgical repair of ruptured thoracic and thoracoabdominal aortic aneurysms. Br J Surg. 2002;89:442-5.

13. Barbato JE, Kim JY, Zenati M, Abu-Hamad G, Rhee RY, Makaroun MS, et al. Contemporary results of open repair of ruptured descending thoracic and thoracoabdominal aortic aneurysms. J Vasc Surg. 2007;45:667-76.

14. Girardi LN, Krieger KH, Altorki NK, Mack CA, Lee LY, Isom OW. Ruptured descending and thoracoabdominal aortic aneurysms. Ann Thorac Surg. 2002;74: 1066-70.

15. Lemaire SA, Jones MM, Conklin LD, Carter SA, Criddell MD, Wang XL, et al. Randomized comparison of cold blood and cold crystalloid renal perfusion for renal protection during thoracoabdominal aortic aneurysm repair. J Vasc Surg. 2009; 49:11-9.

16. Johansson G, Markström U, Swedenborg J. Ruptured thoracic aortic aneurysms: a study of incidence and mortality rates. J Vasc Surg. 1995;21:985-8.

17. Gopaldas RR, Huh J, Dao TK, LeMaire SA, Chu D, Bakaeen FG, et al. Superior nationwide outcomes of endovascular versus open repair for isolated descending thoracic aortic aneurysm in 11,699 patients. J Thorac Cardiovasc Surg. 2010; 140:1001-10.

18. Crawford ES, Hess KR, Cohen ES, Coselli JS, Safi HJ. Ruptured aneurysm of the descending thoracic and thoracoabdominal aorta: analysis according to size and treatment. Ann Surg. 1991;213:417-26.

19. Jonker FH, Verhagen HJ, Lin PH, Heijmen RH, Trimarchi S, Lee WA, et al. Outcomes of endovascular repair of ruptured descending thoracic aortic aneurysms. Circulation. 2010;121:2718-23.

20. Patel HJ, Williams DM, Upchurch GR Jr, Dasika NL, Deeb GM. A comparative analysis of open and endovascular repair for the ruptured descending thoracic aorta. J Vasc Surg. 2009;50:1265-70.

21. Jonker FHW, Trimarchi S, Verhagen JM, Moll FL, Sumpio BE, Muhs BE. Metaanalysis of open versus endovascular repair for ruptured descending thoracic aortic aneurysms. J Vasc Surg. 2010;51:1026-32. 
22. Semba CP, Kato N, Kee ST, Lee GK, Mitchell RS, Miller DC, et al. Acute rupture of the descending thoracic aorta: repair with use of endovascular stent-grafts. $J$ Vasc Interv Radiol. 1997;8:337-42.

23. Makaroun MS, Dillavou ED, Kee ST, Sicard G, Chaikof E, Bavaria J, et al. Endovascular treatment of thoracic aortic aneurysms: results of the phase II multicenter trial of the GORE TAG thoracic endoprosthesis. J Vasc Surg. 2005;41:1-9.

24. Egorova N, Giacovelli J, Greco G, Gelijns A, Kent CK, McKinsey JF. National outcomes for the treatment of ruptured abdominal aortic aneurysm: comparison of open versus endovascular repairs. J Vasc Surg. 2008;48:1092-100.

25. Preventza O, Wheatley GH III, Ramaiah VG, Rodriguez-Lopez JA, Williams J, Olsen D, et al. Management of endoleaks associated with endovascular treatment of descending thoracic aortic diseases. J Vasc Surg. 2008;48:69-73.

26. De Bruin JL, Baas AF, Buth J, Prinssen M, Verhoeven EL, Cuypers PW, et al. Long-term outcome of open or endovascular repair of abdominal aortic aneurysm. N Engl J Med. 2010;362:1881-9.

27. United Kingdom EVAR Trial Investigators, Greenhalgh RM, Brown LC, Powell JT, Thompson SG, Epstein D, Sculpher MJ, et al. Endovascular versus open repair of abdominal aortic aneurysm. N Engl J Med. 2010;362:1863-7.

Key Words: aorta, aneurysm, rupture, surgery

\section{Discussion}

Dr A. DeAnda (New York, New York). Dr Gaudino-thank you for your nice presentation, and thank you for providing me with the manuscript ahead of time to review. I want to congratulate my colleagues up the street for their excellent results.

I have 3 questions. First, when you look at your data and divide it between the TAAAs and DTAs, the mortality rate for the DTAs is actually higher than the mortality rate for the TAAAs, by 3-fold, approximately, whether or not they were ruptured or intact. I think this is a little bit different than at least my experience, which is that the TAAAs tend to be a bigger operation, with less-positive results. It is usually reversed in comparison with DTAs. So my first question is: How do you explain these mortality rates?

My second question is in reference to an editorial comment in the manuscript. A lot of these patients were presenting with, on average, a 7-cm aneurysm, and you posit that this may be because of a reluctance of the referring physicians to send these patients earlier. But could this not be just that these patients are asymptomatic up to the point of rupture?

Finally, you did not mention it in your talk, but in your manuscript, you talk about the use of endovascular approaches. What you have mentioned is that the results of stenting are not as good as those of open repair, and you give some very excellent reasons why that may be the case.

So, maybe for the audience, you could expand on that a little bit-about what you think the role of endovascular treatment is for the ruptured aneurysm. Once again-nice talk.

Dr Gaudino. Thanks, Dr DeAnda, for your nice comments, and obviously, your points are very well taken.
For the difference in mortality between DTAs and TAAAs, I guess there is a major selection bias when these 2 patient populations are compared, because for the DTAs, you really have a solid TEVAR alternative. As surgeons, we are seeing only those patients that you cannot treat with TEVAR, so we are probably getting the sicker or the more complicated patients; whereas for TAAAs, the TEVAR alternative is much less solid, and so we are getting the whole spectrum of patients.

So if I can use these words, we are getting the good and the bad for the TAAAs and only the bad for the DTAs. So this is a possible explanation of your very well taken first point.

Regarding the second, I agree. Unfortunately, most of these patients were transferred from an outside referral hospital, so we do not have a very complete history of those patients. We do not know how many of them had a previous known aneurysm, and for how many of them the rupture was the first clinical presentation of an asymptomatic aneurysm.

I guess that there can be some reluctance to refer a patient for open repair, and this probably applies more to TAAAs than to DTAs. But again, unfortunately, I do not have the numbers to answer this particular question.

You point out the very important point that we do not have a TEVAR group in our study, so we cannot really extrapolate on the basis of our own data on the role of TEVAR. I can say that this result compared fairly well with most of the published TEVAR series, but the comparison of different series from different institutions obviously has limited scientific value.

So this is something that probably cannot be answered on the basis of our data. It is probably related to the experience and the knowledge of the aortic surgeon. Maybe the senior author who is in the audience would later comment on that particular point.

Dr J. Bavaria (Philadelphia, Pennsylvania). So-great presentation, interesting data.

Maybe the next big area of statistics in these kinds of cases is what I would call actuarial statistics. You had a $14 \%$ mortality rate, but then you did a propensity analysis on 61 patients, and the mortality rates were very low in that group, which means that the mortality rates in the other 39 were probably off the wall.

So my question to you is: Can you go the other side and say whether there is a patient population for whom, based on the actuarial statistics, diabetes, plus shock, plus et cetera, these factors would define futility here?

Could you go into those 39 in your preoperative room and say-maybe Len should answer this-but is there a group of patients from these data that you could teach us not to do? 
Dr Gaudino. Yes, that is a very good point. If you look even at the results of the univariate analysis, you realize that what really makes the difference is shock. Patients with preoperative shock had $40 \%$ mortality; whereas, patients without shock had a more or less $8 \%$ mortality rate.

So if you compare patients without shock to the general population, there is no statistically significant difference in mortality; whereas, if you compare patients with shock with the overall population, this difference becomes highly significant.

So what really makes the difference, and this is not surprising, is the preoperative hemodynamic condition. For the patient in shock, preoperative mortality is at least $30 \%$. Even on the basis of the simple univariate analysis, you can see this result fairly well. The propensity matching matched the shock in the rupture group with the few patients of the intact group that were in shock, and so we lose statistical significance in looking at the difference. But the most important predictive variable is definitely preoperative shock.

Dr F. Beyersdorf (Freiburg, Germany). I would like to congratulate you on these fantastic results in ruptured descending thoracoabdominal aneurysms. We are choosing just the opposite approach. That means the vast majority of all ruptured DTAs and TAAAs are getting TEVAR, and this works extremely well and fast.

Your results are really great, and $40 \%$ mortality in ruptured DTAs is fantastic, especially if you have such a relatively high percentage of patients in shock. However, you have also spinal cord drainage in $67 \%$; we would like to do that, even if we are using TEVAR, but we can never do it because we rush the patients with ruptured aneurysms into the operating room.

So the question is: What exactly is a ruptured DTA in your series? Open rupture means hemothorax, and it is a true emergency. Of course, penetrated ones may also have been included in your series.

In our experience at least, our results have been improved tremendously by using TEVAR because it is a much faster procedure. Even if you can deal with only the ruptured side, you can still deal with the other problems a couple of weeks or months later.

My second question is: Given the 67\% spinal cord drainage, what percentage of your patients really had ruptured aneurysm in your series?

Dr Gaudino. Well, obviously the 27 patients that were in shock were those in whom the rupture was not covered, and they were among those $35 \%$ who did not receive the spinal drain. The other patients were more or less hemodynamically stable. We really strongly believe in the importance of the spinal drain, so we make every effort to have it placed in before surgery.
If you look at the literature regarding the natural history of ruptured DTAs and TAAAs, $93 \%$ of these patients die before reaching the hospital, so you are really dealing with survivors. I guess the majority of the patients we see do not have a free rupture of the aneurysm; otherwise, they would not reach the hospital.

For those that do reach the hospital, more or less one third of them are very unstable, so you do not have time to place the drain or do many other things. You just rush to the operating room. But for the majority, you probably have the possibility of at least putting in your drain before going into the operating room.

Dr L. Girardi (New York, New York). Just to answer Dr Bavaria's question, we did do a slightly more complicated statistical analysis that we ran out of time for here, and it will be in the article. But the interesting thing I think about it, and it surprised me initially, is that the rupture in and of itself is not the event that seems to make a big difference, as long as the patient is not unstable. The minute you throw in rupture with instability, it changes everything, and the perioperative mortality and incidence of every possible complication increases dramatically.

When you compare these results to most series with TEVAR, the initial clinical outcomes are certainly in the same ballpark. I think, for those patients who are unstable, TEVAR is definitely a good approach, especially in a smaller hospital where a lot of these patients present; it is probably the approach to use for those patients, as long as that facility has the technical capability of performing that procedure in a timely fashion.

There have been arguments that even unstable patients should just be sent to tertiary care. I guess it just depends on the distance, but trying to do that in New York City really will not work. So we get a lot of patients who are more "stable," and most of the ones that were in some level of shock came in within our system.

So we are not saying that TEVAR does not have a role. We think it actually does, and it has dramatically reduced the perioperative outcome mortality. But the reinterventions-the long-term survival-does not seem to be as good, at least in smaller series, so we think this is a good approach for a lot of patients.

Dr B. Yang (Ann Arbor, Michigan). I just want to extend the discussion on the management of patients with ruptured aorta and hemorrhagic shock. I had a patient with an acute on chronic type B dissection, ruptured DTA, and hemorrhagic shock. He was a Jehovah's Witness. I did not think he would have survived an immediate open repair without blood transfusion, had I taken him to the operating room for a definitive open repair.

What we did was to place a stent graft to cover a new tear between the true lumen and new false lumen to stop the bleeding temporarily. We waited for a month for him to recover from hemorrhagic shock and anemia. Then we 
performed the definitive open repair of his 9-cm DTA. He was discharged without any complications.

I think TEVAR can be a great alternative to temporarily stop the bleeding from ruptured aorta for suitable patients when those patients are not candidates for open repair. It gives the patients the opportunity to recover, and surgeons the opportunity to perform the definitive open repair safely, later. 